\section{IBM Displaced}

The United States Air Force has now chosen to buy computers from Burroughs for the second phase of its programme of automation at its bases around the world. This is a plan to install linked computers in USAF bases to deal with problems of logistics. The contract was originally put out to tender last April, and was won by IBM with a bid of $\$ 114$ million. Honeywell, which had submitted a bid of only $\$ 54$ million, complained to the General Accounting Office. As a result of this, the Comptroller-General ordered the cancellation of the IBM contract, despite the Air Force's assertion that price was only one of five factors to be considered, and that only IBM, to use its own words, "satisfied these areas of response". All four manufacturers tendered again, and Burroughs' winning bid was to provide 135 of its "third-generation" B.3500 machines for $\$ 60$ million.

IBM has confessed itself disappointed by the final decision, claiming the superiority of its products. The USAF, which announced details only of the winning bid on both occasions, seems unrepentant. It has confused a none too Jucid issue by saying that the tenders for the second selection "were markedly different from the original submission in terms of capacities, speeds and, in some cases, processing techniques". It also claims that the delay caused by the intervention of the Comptroller-General cost $\$ 18$ million, so that the American taxpayer need only congratulate himself on a saving of $\$ 36$ million. Honeywell has pronounced itself satisfied that the original complaint has been shown to have been justified; the exercise seems to have lost Honeywell no favour with the US Government, for the company has just received an order to lease twenty-two computers, worth $\$ 8.5$ million, to the Department of Defense.

Burroughs had won the contract for the first phase of the same programme, a $\$ 24$ million order to provide computers for organizing supplies at air force bases, so that the USAF will doubtless find advantages in having standard equipment for base logistics. The first two systems of the second phase will be delivered in March, and two further systems will be installed at Sheppard Air Force Base, Texas, in April and May. These will be used for training. A test programme will begin at Langley Air Force Base, Virginia, in September and, if the results of this are satisfactory, the computers will be installed at bases around the world during 1969 and the first half of 1970.

\section{Supersonic Plans}

THE introduction of supersonic transport aircraft is bound to increase problems of air transport control and flight planning. As well as flying three times as fast as aircraft now in service, supersonic aircraft will fly much higher, at between 16 and 21 kilometres. Meteorologists, familiar with the problems of longrange forecasting, are already beginning to wonder how the supersonics are going to affect them. Some results of this process of looking ahead have now appeared in the form of a report from the World Meteorological Organization called Meteorological Problems in the Design and Operation of Supersonic Aircraft. The report is written by $\mathbf{R}$. F. Jones, R. M. MeInturff and S. Teweles.
The difficulties of the sonic boom are already familiar enough. As well as the regular boom which the aircraft makes, the report discusses the phenomenon of "superboom", which is thought to be caused by the simultaneous arrival at the observation point of shock waves from two distinct parts of the flight path. Overpressures as great as 3.6 mbar have been recorded in low level tests, nearly five times as great as the nominal overpressures which the SSTs are expected to produce. It may be possible to eliminate superbooms by avoiding turning manoeuvres or supersonic acceleration in level flight, but atmospheric turbulence may affect the issue by producing quite rapid accelerations and changes in aircraft attitude. Actual experience with the first supersonic airliners will be needed before the position is clear.

The actual incidence of the boom may also be affected by unscheduled changes of flight plan. The thrust of a jet engine decreases with increasing temperature-BOAC, for example, has estimated that a five-degree increase in temperature produces a 25 per cent deterioration in acceleration between Mach $1 \cdot 1$ and $2 \cdot 0$. And because the SSTs will fly much higher than existing aircraft, information about tem. peratures is relatively more scarce. Most of the handicap of higher temperatures is experienced in the trans-sonic phase of the flight, between Mach 0.8 and $1 \cdot 2$.

The problems of turbulence, and its effects on aircraft, are not well understood. One problem, as the report explains, is that aircraft in flight filter from the whole spectrum of turbulence those frequencies to which they are most susceptible. Thus results with one aircraft may not be duplicated with another. Short wavelength disturbances may affect the fatigue life of the aircraft without actually making passengers feel uncomfortable, while long wavelengths may move the aircraft bodily but smoothly, without imposing great strains on its structure. Between these two extremes there are wavelengths which cause the aircraft to roll or pitch. Some turbulence is associated with cloud structures, and may be possible to avoid, because heavy cloud formations can be detected by radar. Clear air turbulence is a more severe problem, and there is evidence that it will be experienced at SST cruising heights. In flight, warning devices may help, but only if they can detect CAT 100 miles ahead of the aircraft.

There will also be a danger of large doses of radiation, because at supersonic aircraft heights the atmosphere will be too rarefied to provide a protective screen. The report confirms the suggestion that galactic cosmic rays, a continuous background through which the SS'T's will have to fly, will not be a hazard. But there does seem to be a danger if exceptional solar events such as solar flares are ignored. The report contains a calculation by M. Haurwitz, previously unpublished, which shows that for a hypothetical event of the magnitude of the event on November 12, 1960, passengers on a three hour flight at $21 \mathrm{~km}$ would receive a dose of radiation twice as large as that recommended for a whole year. Warning devices in the aircraft, and careful preflight planning, will be necessary to minimize the dangers. Another hazard is the presence of ozone in the atmosphere; even small concentrations are poisonous, and it is thought that concentrations of more than $0.1 \mathrm{ppm}$ by volume 